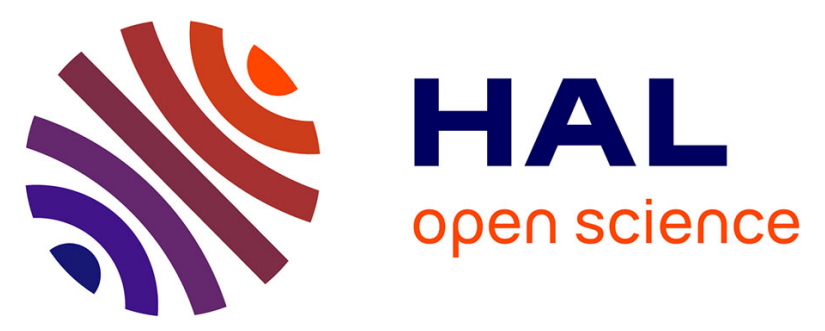

\title{
The sphingosine-1-phosphate receptor agonist FTY720 dose dependently affected endothelial integrity in vitro and aggravated ventilator-induced lung injury in mice
}

Holger Christian Müller, Andreas Christian Hocke, Katharina Hellwig, Birgitt Gutbier, Harm Peters, Stefanie Maria Schönrock, Thomas Tschernig, Andreas Schmiedl, Stefan Hippenstiel, Philippe Dje N'Guessan, et al.

\section{To cite this version:}

Holger Christian Müller, Andreas Christian Hocke, Katharina Hellwig, Birgitt Gutbier, Harm Peters, et al.. The sphingosine-1-phosphate receptor agonist FTY720 dose dependently affected endothelial integrity in vitro and aggravated ventilator-induced lung injury in mice. Pulmonary Pharmacology \& Therapeutics, 2011, 10.1016/j.pupt.2011.01.017 . hal-00753947

\section{HAL Id: hal-00753947 https://hal.science/hal-00753947}

Submitted on 20 Nov 2012

HAL is a multi-disciplinary open access archive for the deposit and dissemination of scientific research documents, whether they are published or not. The documents may come from teaching and research institutions in France or abroad, or from public or private research centers.
L'archive ouverte pluridisciplinaire HAL, est destinée au dépôt et à la diffusion de documents scientifiques de niveau recherche, publiés ou non, émanant des établissements d'enseignement et de recherche français ou étrangers, des laboratoires publics ou privés. 


\section{Accepted Manuscript}

Title: The sphingosine-1-phosphate receptor agonist FTY720 dose dependently affected endothelial integrity in vitro and aggravated ventilator-induced lung injury in mice

Authors: Holger Christian Müller, Andreas Christian Hocke, Katharina Hellwig, Birgitt

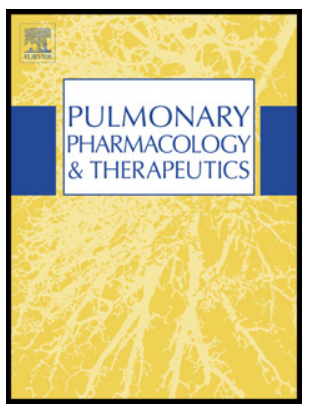

Gutbier, Harm Peters, Stefanie Maria Schönrock, Thomas Tschernig, Andreas

Schmiedl, Stefan Hippenstiel, Philippe Dje N'Guessan, Simone Rosseau, Norbert

Suttorp, Martin Witzenrath

PII:

S1094-5539(11)00039-3

DOI:

10.1016/j.pupt.2011.01.017

Reference: $\quad$ YPUPT 1092

To appear in: Pulmonary Pharmacology \& Therapeutics

Received Date: 24 June 2010

Revised Date: 5 December 2010

Accepted Date: 24 January 2011

Please cite this article as: Müller HC, Hocke AC, Hellwig K, Gutbier B, Peters H, Schönrock SM, Tschernig T, Schmiedl A, Hippenstiel S, N'Guessan PD, Rosseau S, Suttorp N, Witzenrath M. The sphingosine-1-phosphate receptor agonist FTY720 dose dependently affected endothelial integrity in vitro and aggravated ventilator-induced lung injury in mice, Pulmonary Pharmacology \& Therapeutics (2011), doi: 10.1016/j.pupt.2011.01.017

This is a PDF file of an unedited manuscript that has been accepted for publication. As a service to our customers we are providing this early version of the manuscript. The manuscript will undergo copyediting, typesetting, and review of the resulting proof before it is published in its final form. Please note that during the production process errors may be discovered which could affect the content, and all legal disclaimers that apply to the journal pertain. 
The sphingosine-1-phosphate receptor agonist FTY720 dose dependently affected endothelial integrity in vitro and aggravated ventilator-induced lung injury in mice.

Holger Christian Müller ${ }^{\mathrm{a}}$, Andreas Christian Hocke ${ }^{\mathrm{a}}$, Katharina Hellwig ${ }^{\mathrm{a}}$, Birgitt Gutbier $^{\mathrm{a}}$, Harm Peters ${ }^{\mathrm{b}}$, Stefanie Maria Schönrock ${ }^{\mathrm{a}}$, Thomas Tschernig $^{\mathrm{c}}$, Andreas Schmiedl ${ }^{d}$, Stefan Hippenstiel ${ }^{a}$, Philippe Dje N'Guessan ${ }^{a}$, Simone Rosseau ${ }^{\mathrm{a}}$, Norbert Suttorp $^{\mathrm{a}}$, Martin Witzenrath ${ }^{\mathrm{a}}$

${ }^{a}$ Department of Infectious Diseases and Pulmonary Medicine, Charité - Universitätsmedizin Berlin, Charitéplatz 1, 10117 Berlin, Germany

${ }^{\mathrm{b}}$ Department of Nephrology, Charité - Universitätsmedizin Berlin, Charitéplatz 1, 10117 Berlin, Germany

${ }^{\mathrm{c}}$ Institute for Anatomy and Cell Biology, Saarland University Faculty of Medicine, Kirrberger Straße, Building 61, 66421 Homburg Saar, Germany

${ }^{\mathrm{d}}$ Institute for Functional and Applied Anatomy, Medical School of Hannover, Carl-Neuberg-Str. 1, 30625 Hannover, Germany

\section{Corresponding author}

Holger C. Müller

Charité - Universitätsmedizin Berlin

Dept. of Infectious Diseases and Pulmonary Medicine

Charitéplatz 1; 10117 Berlin; Germany

Phone: +49 30450653 336; FAX: +49 30450553979

holger.mueller@charite.de 


\section{$\underline{\text { Abstract }}$}

Lung barrier protection by Sphingosine-1 Phosphate (S1P) has been demonstrated experimentally, but recent evidence suggests barrier-disruptive properties of high systemic S1P concentrations. The S1P analog FTY720 recently gained an FDA approval for treatment of multiple sclerosis. In case of FTY720 treated patients experiencing multiple organ dysfunction syndrome the drug may accumulate due to liver failure, and the patients may receive ventilator therapy. Whereas low doses of FTY720 enhanced endothelial barrier function, data on effects of increased FTY720 concentrations are lacking. We measured transendothelial resistance (TER) of human umbilical vein endothelial cell (HUVEC) monolayers, performed morphologic analysis and measured apoptosis by TUNEL staining and procaspase-3 degradation in HUVECs stimulated with FTY720 (0.01-100 $\mu \mathrm{M})$. Healthy C57BL/6 mice and mice ventilated with $17 \mathrm{ml} / \mathrm{kg}$ tidal volume and $100 \%$ oxygen for $2 \mathrm{~h}$ were treated with 0.1 or $2 \mathrm{mg} / \mathrm{kg}$ FTY720 or solvent, and lung permeability, oxygenation and leukocyte counts in BAL and blood were quantified. Further, electron microscopic analysis of lung tissue was performed. We observed barrier protective effects of FTY720 on HUVEC cell layers at concentrations up to $1 \mu \mathrm{M}$ while higher concentrations induced irreversible barrier breakdown accompanied by induction of apoptosis. Low FTY720 concentrations $(0.1 \mathrm{mg} / \mathrm{kg})$ reduced lung permeability in mechanically ventilated mice, but $2 \mathrm{mg} / \mathrm{kg}$ FTY720 increased pulmonary vascular permeability in ventilated mice accompanied by endothelial apoptosis, while not affecting permeability in nonventilated mice. Moreover, hyperoxic mechanical ventilation sensitized the pulmonary vasculature to a barrier disrupting effect of FTY720, resulting in worsening of ventilator induced lung injury. In conclusion, the current data suggest FTY720induced endothelial barrier dysfunction, which was probably caused by proapoptotic effects and enhanced by mechanical ventilation. 
Keywords: Ventilator-induced lung injury, FTY720, Vascular permeability, acute lung injury, apoptosis

\section{Introduction}

Multiple organ dysfunction syndrome accounts for high morbidity and mortality rates and is frequently associated with vascular leakage. In the lung, the loss of vascular barrier integrity evokes pulmonary edema formation, surfactant dysfunction, and impaired lung compliance, resulting in deterioration of pulmonary gas exchange and eventually the requirement of hyperoxic mechanical ventilation (MV). Although being a life saving intervention in acute respiratory failure without an alternative, MV may evoke ventilator-induced lung injury (VILI), which conjointly with hyperoxia further enhances inflammation and lung permeability, thereby aggravating the initial lung injury.

FTY720 [2-amino-2-(2-[4-octylphenyl]ethyl)-1,3-propanediol] is a structural analog of the endogenous sphingolipid Sphingosine-1 Phosphate (S1P). The five known S1P receptors (S1PR1-5) are ligated by FTY720, with relatively low affinity to S1P2 and S1P3. Comparable with S1P, FTY720 has potent immunomodulatory effects by reducing total numbers of circulating lymphocytes via inhibition of $\mathrm{T}$ - and $\mathrm{B}$-Cell egress from lymphoid tissues[1]. Thereby, FTY720 prevented acute graft rejection and destruction in animal studies[2] as well as in clinical trials in renal transplant patients[3-5]. Notably, a therapeutic effect of FTY720 for the treatment of multiple sclerosis has been evidenced by clinical trials and FTY720 only recently gained FDA approval (NDA 022527) for the treatment of multiple sclerosis [6-9].

Beside immunomodulatory properties, S1P and FTY720 may impact on the regulation of pulmonary endothelial barrier function[1,10]. Vascular endothelial cells primarily express S1P1, S1P2 and S1P3. In the lungs, physiologic S1P 
concentrations $(0.5-1 \mu \mathrm{M})$ may increase microvascular barrier integrity via ligation of S1P1[10] by promoting actin cytoskeletal regulatory protein recruitment to membrane lipid rafts and Gi-coupled signalling to cytoskeletal elements via Rac GTPase[11-13]. Infusion of S1P or FTY720 reduced lung microvascular leakage in different models of lung injury, including intratracheal Lipopolysaccharide (LPS) application in mice[14], murine and canine ventilator induced lung injury[15], acute necrotizing pancreatitisassociated lung injury in rats[16], and ischemia/reperfusion injury following syngeneic rat lung transplantation[17]. In accordance, Sphingosine-Kinase 1 (SphK1) deficient mice were more susceptible to LPS-induced lung injury as compared to their wild type littermates[18]. Moreover, even a S1P receptor independent increase of endothelial barrier function by FTY720 has been observed in vitro[19]. However, S1P at higher concentration $(>5 \mu \mathrm{M})$ mediates RhoA dependent barrier disruption through ligation of S1P2 and S1P3, which couple to $G_{i}, G_{q}$ and $G_{12 / 13}[10,20]$. Of note, even the selective S1P1 agonist SEW-2871 produced concentration-dependent barrierregulatory responses in murine lungs, evoking significant alveolar-capillary barrier disruption in higher concentrations[21].

FTY720 has a long half life of approximately 8 days, exclusively employs hepatic metabolism via the cytochrome p450 4F2 (CYP4F2) and has a huge volume of distribution. Thus, accumulation of FTY720 is probable in patients with multiple organ dysfunction syndrome [22-25]. Considering the complex role of S1P receptor signaling in the regulation of endothelial barrier function, relevant risks for critically ill FTY720-treated patients need to be envisioned.

In the current study, we analyzed concentration-dependent effects of FTY720 on endothelial barrier function in vitro and in healthy mice, and investigated the impact of different FTY720 dosing on lung injury evoked by mechanical ventilation and hyperoxia in mice. 


\section{Methods}

\subsection{Transcellular Electrical Resistance (TER) of Endothelial Cells}

Human umbilical cord vein endothelial cells (HUVEC) were isolated as described[26] and grown on evaporated gold electrodes, connected to an electrical cell-substrate impedance system (Applied Biophysics, Troy, USA NY). Cells were exposed to different concentrations of FTY720 (Cayman, Ann Arbor, USA) ranging from 0.01 to $100 \mu \mathrm{M}$ and TER values from each microelectrode were continuously monitored and normalized as the ratio of measured resistance to baseline resistance.

\subsection{Preparation of human endothelial cells and F-actin staining}

HUVEC obtained from collagenase digestion were washed, resuspended, cultivated in MCDB 131-10\% FCS and seeded onto 24-well Thermanox slides (Nunc, Germany) [26]. Studies were performed using confluent endothelial cell monolayers in their second passage. HUVEC were incubated with 1 or $100 \mu \mathrm{M}$ FTY720 for $1 \mathrm{~h}$. Slides were fixed for $20 \mathrm{~min}$ in $3 \%$ paraformaldehyde. Permeabilization of cell membranes was performed using $1 \%$ Triton $\mathrm{X} 100$, and $\mathrm{F}$-actin was stained with phalloidin Alexa 488 (Molecular Probes, Invitrogen) as described previously[26]. Slides were analyzed using a Pascal 5 confocal scanning laser microscope (Zeiss, Jena, Germany) equipped with an air-cooled argon laser (Axioskop 2 Mot microscope, Zeiss). Alexa 488 fluorescence was excited with $488 \mathrm{~nm}$ argon-ion laser beam and imaged using a NT80/20/488 beam splitter and a $505 \mathrm{~nm}$ longpass emission filter.

\subsection{TUNEL staining}

For the assessment of apoptosis, HUVECs grown on gelatin-coated Thermanox slides were stimulated as indicated, washed twice, and incubated in a humidified 
atmosphere. Cells were fixed in paraformaldehyde $4 \%$, washed, and DNA strand breaks were labeled by Fluorescein (FITC)-dUTPnick-endlabeling (TUNEL), and enhanced by application of Alexa 488 anti FITC antibody $\left(1: 1,000,1 \mathrm{~h}\right.$ at $\left.37^{\circ} \mathrm{C}\right)$ as described previously[27]. F-actin was visualized by marking with Alexa 546-labeled phalloidin (1:200, $30 \mathrm{~min})$. Staurosporin $10 \mu \mathrm{M}$ was used as a positive control for apoptosis. Staurosporin treated cells, in which the enzymatic reaction leading to a positive signal of fluorescence was not performed served as negative controls, confirming the TUNEL signal as specific. Analysis of the slides was performed by using a Zeiss Pascal 5 confocal microscope (objective lens: Plan-Apochromat 63x/1.4) (Zeiss, Jena, Germany).

\subsection{Pro Caspase 3 degradation}

HUVECs were grown to confluent cell layers and incubated with indicated concentrations of FTY720 or buffer for $1 \mathrm{~h}$. After trypsination, cells were washed and lysed in buffer containing Triton X-100, subjected to SDS-PAGE, and blotted on Hybond-ECL membrane (Amersham Biosciences, Freiburg, Germany). Immunodetection of procaspase 3 was carried out with specific antibody (Upstate Biotechnology, Lake Placid, USA). In all experiments, actin (Santa Cruz Biotechnologies, Santa Cruz, USA) was detected simultaneously to confirm equal protein load. Both proteins were visualized by incubation with secondary IRDye800or Cy5.5-labeled antibodies (Odyssey infrared imaging system, LI-COR).

\subsection{Mice}

All procedures were approved by local and governmental (LAGeSo, Berlin) authorities. VILI was induced as decribed[28]. In summary, female C57BL/6 mice (11-15 weeks; Charles River, Sulzfeld, Germany) were anesthetized by repetitive 
intraperitoneal injections of xylazine every $50 \mathrm{~min}(25 \mu \mathrm{g} / \mathrm{g})$ and ketamine $(125 \mu \mathrm{g} / \mathrm{g})$. Body temperature was measured continuously using a rectal probe and maintained at $37^{\circ} \mathrm{C}$ by a heating pad. After tracheotomy and int ubation, mice were ventilated (MiniVent, Harvard Apparatus, March, Germany), and airway pressure was raised to $35 \mathrm{cmH}_{2} \mathrm{O}$ for 5 seconds for lung recruitment, followed by ventilation with $7 \mathrm{ml} / \mathrm{kg}$ tidal volume $\left(\mathrm{V}_{\mathrm{T}}\right)$, positive endexspiratory pressure $(\mathrm{PEEP})=6 \mathrm{cmH}_{2} \mathrm{O}$, and inspiratory fraction of oxygen $\left(\mathrm{FiO}_{2}\right)=1$. A carotid artery catheter was placed for blood pressure monitoring and continuous infusion of sodium chloride $0.9 \%$ containing $100 \mathrm{mmol} / \mathrm{l}$ $\mathrm{HCO}_{3}{ }^{-}$at $350 \mu \mathrm{l} / \mathrm{h}$ during the ventilation period.

When baseline conditions were established, ventilator settings were changed to $17 \mathrm{ml} / \mathrm{kg}$ tidal volume and PEEP $=0 \mathrm{cmH}_{2} \mathrm{O}$. At termination of experiments mice were sacrificed by exsanguination via the carotid artery catheter. Non-ventilated mice did not undergo surgery and were spontaneously breathing $\left(\mathrm{FiO}_{2}=0.21\right)$.

Mice were injected with either solvent or $0.1 \mathrm{mg} / \mathrm{kg}$ or $1 \mathrm{mg} / \mathrm{kg}$ FTY720, dissolved in $0.9 \%$ saline, $30 \mathrm{~min}$ before preparation. Mice in the high dose group received a second dosage of $1 \mathrm{mg} / \mathrm{kg}$ after one hour of ventilation while the other groups received injections of solvent. Non-ventilated mice were injected with same dosages in matched intervals when indicated.

\subsection{Measurement of oxygenation}

$\mathrm{P}_{\mathrm{a}} \mathrm{O}_{2}$ was quantified in arterial blood of all animals subjected to MV (ABL700, Radiometer-Copenhagen). Oxygenation was expressed as $\mathrm{p}_{2} \mathrm{O}_{2} / \mathrm{F}_{i} \mathrm{O}_{2}$ (P/F ratio).

\subsection{Lung vascular permeability}

Human serum albumin (HSA; 1 mg; Baxter, Unterschleißheim, Germany) was injected via the carotid artery catheter or the tail vein in ventilated or non-ventilated 
mice, respectively, 90 min before termination of the experiment. Mice were sacrificed and bronchoalveolar lavage (BAL) was performed with $2 \times 800 \mu$ l phosphate buffered saline (PBS). BAL and plasma HSA levels were quantified by ELISA (Bethyl Laboratories, USA). Permeability was assessed by calculating HSA BAL/plasma ratio.

\subsection{BAL and blood leukocyte counts}

BAL cells were counted by hemocytometer and differentiated by flow cytometry (FACSCalibur, BD, Heidelberg, Germany) analyzing forward and side scatter characteristics and expression of surface antigens CD45, Gr-1 and F4-80. Blood leukocytes were counted and differentiated by flow cytometry analyzing CD45 and Gr-1 surface expression using TruCount tubes (BD, Heidelberg, Germany).

\subsection{Electron microscopy}

Lungs were flushed via the pulmonary artery, cut, immersion-fixed $(1.5 \%$ glutaraldehyde, $1.5 \%$ paraformaldehyde in $0.15 \mathrm{M}$ HEPES$)$, rinsed $(0.1 \mathrm{mmol} / \mathrm{l}$ HEPES, $0.1 \mathrm{mmol} / \mathrm{l}$ cacodylate buffer) and osmicated (1\% osmium tetroxide in $0.1 \mathrm{mmol} / \mathrm{l}$ cacodylate buffer). After rinsing in $0.1 \mathrm{mmol} / \mathrm{l}$ cacodylate buffer and distilled water, specimens were stained in half-saturated aqueous uranylacetate solution (1:1). Samples were dehydrated in ascending acetone concentrations, embedded in epon, cut $(70 \mathrm{~nm})$, stained with lead citrate and uranyl-acetate, and analyzed as described previously[29].

\subsection{Statistical analyses}

Data are expressed as mean +/- SEM. For comparism between groups Man-Whithey U-test was used. $P$ values $<0.05$ were considered statistically significant. 


\section{Results}

3.1. FTY720 enhanced or disrupted endothelial cell monolayer integrity, depending on the employed concentration.

Confluent monolayers of human umbilical vein endothelial cells (HUVECs) stimulated with $0.01,0.1$ or $1 \mu \mathrm{M}$ FTY720 showed a dose-dependent increase in TER, and endothelial barrier function was continuously improved during the observation period of 180 min (Fig. 1a). In contrast, $100 \mu \mathrm{M}$ FTY720 rapidly impaired endothelial barrier function. Notably, $10 \mu \mathrm{M}$ FTY720 initially increased TER, which declined below the baseline values during the further observation period. Area under curve (AUC) analysis of TER confirmed this observation (Fig. 1b). Absolute TER values at 60, 90, 120, 180 min revealed increased values when HUVECs were stimulated with 0.01, 0.1 or $1 \mu \mathrm{M}$ FTY720, whereas 10 and $100 \mu \mathrm{M}$ FTY720 reduced TER (Fig. 1c) as compared to untreated HUVEC monolayers.

\subsection{High FTY720 concentration causes endothelial cell stress and damage}

To further analyze the endothelial barrier-increasing effect of low FTY720 concentrations and the barrier-disrupting effects of high concentrations, cell morphology of endothelial cells was evaluated. Taking the results of the TER experiments in account HUVECs were stimulated with 1 or $100 \mu \mathrm{M}$ FTY720 or solvent for 60 min. HUVECs stimulated with $1 \mu \mathrm{M}$ FTY720 displayed a morphology indistinguishable from non stimulated HUVECs. Stimulation with $100 \mu \mathrm{M}$ FTY720 led to severe cell detachment from the endothelial cell layer (Fig. 2a). 


\subsection{High FTY720 concentration induces apoptosis in endothelial cells}

HUVECs were incubated with solvent or 1,10 or $100 \mu \mathrm{M}$ FTY720 for 60 min and TUNEL staining was performed to evaluate for apoptosis. In cells stimulated with solvent, 1 or $10 \mu \mathrm{M}$ FTY720, no TUNEL positive stained cells were detectable while incubation with $100 \mu \mathrm{M}$ induced apoptosis (Fig 2b). To further enhance evidence of FTY720 induced apoptosis, HUVECs were incubated with $0.1,10$ or $100 \mu \mathrm{M}$ FTY720 for $60 \mathrm{~min}$, and caspase 3 activation was assessed by analyzing the degradation of procaspase 3 by western blot technique. After $60 \mathrm{~min}, 100 \mu \mathrm{M}$ FTY720 induced degradation of procaspase 3 , which was not detected after incubation with solvent or 0.1 or $10 \mu \mathrm{M}$ FTY720, suggesting apoptosis to be one underlying mechanism of FTY720 induced barrier breakdown (Fig. 2c).

\subsection{FTY720 treatment did not evoke lung injury in non-ventilated mice}

To evaluate the impact of increasing FTY720 dosage on lung permeability in vivo, healthy mice were treated with $0.1 \mathrm{mg} / \mathrm{kg}$ or $2 \mathrm{mg} / \mathrm{kg}$ FTY720. Pulmonary vascular permeability was quantified, and differential white blood cell count was performed. In healthy mice, FTY720 (0.1 and $2 \mathrm{mg} / \mathrm{kg}$ ) did not alter lung permeability (Fig. 3a), decreased circulating lymphocytes, and did not affect monocyte and PMN counts (Fig. 3b).

\subsection{High dose FTY720 aggravated lung injury in mechanically ventilated mice}

MV with $17 \mathrm{ml} / \mathrm{kg} \mathrm{V}_{\mathrm{T}}$ increased pulmonary permeability in healthy mice, and treatment with $0.1 \mathrm{mg} / \mathrm{kg}$ FTY720 significantly attenuated pulmonary permeability provoked by MV. In contrast, mice treated with $2 \mathrm{mg} / \mathrm{kg}$ FTY720 developed dramatically increased pulmonary permeability as compared to untreated ventilated 
mice (Fig. 4a). FTY720 did not alter mean systemic arterial blood pressure (data not shown).

As permeability edema may impair pulmonary gas exchange, arterial $\mathrm{pO}_{2}\left(\mathrm{p}_{\mathrm{a}} \mathrm{O}_{2}\right)$ after $120 \mathrm{~min}$ of MV was quantified. Treatment with $2 \mathrm{mg} / \mathrm{kg} \mathrm{FTY720} \mathrm{impaired} \mathrm{gas}$ exchange reflected by a lower $\mathrm{p}_{\mathrm{a}} \mathrm{O}_{2}$ in this group, as compared to other groups (ctr. $376.8 \pm 28.9,0.1 \mathrm{mg} / \mathrm{kg}$ FTY720 393,6 \pm 23,63, $2 \mathrm{mg} / \mathrm{kg}$ FTY720 342,5 \pm 29,86 [mmHg]; mean $\pm S D$ ) (Fig. 4b). MV evoked accumulation of neutrophils in BAL fluid. Treatment with FTY720 did not alter recruitment of neutrophils to the lung in VILI (Fig. 4c).

\subsection{High dose FTY720 induced endothelial apoptosis in VILI}

In solvent treated mice, MV evoked edema of the alveolar epithelium, while endothelial injury was observed only sporadically. Non-ventilated mice treated with $0.1 \mathrm{mg} / \mathrm{kg}$ FTY720 showed intact endothelium and epithelium. After $2 \mathrm{~h}$ of MV, mice treated with $0.1 \mathrm{mg} / \mathrm{kg}$ FTY720 developed epithelial edema, while endothelial apoptosis was noticed occasionally. Non-ventilated mice subjected to $2 \mathrm{mg} / \mathrm{kg}$ FTY720 displayed intact epithelium and overall intact endothelial integrity, while few endothelial cells underwent apoptosis. In contrast, $2 \mathrm{~h}$ of MV evoked pronounced endothelial injury in mice treated with $2 \mathrm{mg} / \mathrm{kg} \mathrm{FTY720,} \mathrm{as} \mathrm{displayed} \mathrm{by} \mathrm{endothelial}$ disintegrity and frequent endothelial apoptosis. Moreover, epithelial injury was observed in lungs of mechanically ventilated mice after treatment with $2 \mathrm{mg} / \mathrm{kg}$ FTY720 (Fig. 5).

\section{Discussion}

The current study provided evidence that the S1P analog FTY720, which has recently been approved by the FDA as a novel treatment for multiple sclerosis (NDA 
022527) and has been evaluated as immunosuppressant following renal transplantation may impair endothelial barrier function due to induction of apoptosis at high concentrations in vitro. Moreover, our findings suggested that hyperoxic mechanical ventilation may pave the way for detrimental effects of FTY720 on pulmonary endothelial barrier function by induction of endothelial apoptosis in vivo, thereby further impairing pulmonary gas exchange in mice.

Endothelial barrier function is tightly regulated by various mechanisms including S1Prelated effector systems, and FTY720 acts as a S1P analog[1,10]. In line with previous observations[19,30], low FTY720 concentrations stabilized endothelial barrier function of HUVEC monolayers in the current investigation. However, it has also been reported that particular structural analogs of FTY720 caused endothelial barrier breakdown, indicating a more complex and concentration-dependent effect of FTY720 on the regulation of vascular integrity[31]. Indeed, FTY720 at high concentrations $(10-100 \mu \mathrm{M})$ seriously impaired endothelial barrier function in the current study. Barrier disruptive properties have been reported for S1P2 dependent signaling pathways[32], but FTY720 has virtually no affinity to S1P2 up to concentrations of $10 \mu \mathrm{M}$ [33]. Thus, an additional mechanism for barrier breakdown, possibly in synergism with S1P2 ligation at FTY720 concentrations higher than $10 \mu \mathrm{M}$ may underlie the observed impairment of endothelial barrier function. Here we observed that endothelial barrier disruption by high concentrations $(100 \mu \mathrm{M})$ of FTY720 was accompanied by induction of apoptosis suggesting apoptosis to be one possible underlying effect of FTY720 induced barrier dysfunction. These findings are in line with studies reporting induction of caspase 3 dependent apoptosis by FTY720 in different cell types[34,35].

In humans FTY720 has an elimination half life of more than 8 days under 5 mg daily dosing, and a high volume of distribution exceeding 1000 I [22]. Hepatic impairment 
and interference with CYP4F2 metabolism, which can be confined by other drugs including ketokonazole, led to reduced FTY720 clearance and increase of systemic FTY720 levels[23-25]. Thus, in critically ill patients who suffer from multiple organ dysfunction and receive complex drug therapy, FTY720 levels may likely exceed the aimed therapeutic tissue concentration. Moreover, it is tempting to speculate that FTY720 and endogenous S1P may have particular additive effects. Importantly, enhanced SphK1 activity was observed in phagocytes of septic patients, and SphK1 inhibition augmented the course of fatal sepsis in mice[36]. Therefore, detrimental effects of enhanced SphK1 activity may possibly be further aggravated by increasing FTY720 tissue concentrations in sepsis with multiple organ dysfunction syndrome.

After discovering a barrier disruptive effect of high FTY720 concentrations in primary human endothelial cells we intended to investigate the impact of different FTY720 doses on endothelial barrier function in vivo, and thus decided to quantify pulmonary vascular leakage in mice. In line with various studies in which mice treated with comparable FTY720 doses did not develop serious side effects[37-39], no impact of FTY720 on pulmonary permeability was observed in healthy mice. Notably, in mice treated with $2 \mathrm{mg} / \mathrm{kg}$ FTY720 apoptotic endothelial cells and endothelial barrier disruption were noted by electron microscopic evaluation occasionally, which obviously remained without measurable consequences for overall vascular integrity in healthy mice. However, to model the clinical situation of FTY720 accumulation, use of healthy mice may not be appropriate as accumulation of FTY720 may predominantly occur in critically ill patients. One third of patients in intensive care units are receiving MV[40], frequently with a high fraction of inspiratory oxygen, and increased pulmonary permeability is a hallmark of both ventilator-induced and hyperoxic lung injury[41,42]. Thus, we tested the impact of FTY720 on pulmonary vascular permeability simultaneously affected by MV and hyperoxia. According to 
studies evaluating FTY720 in other models of ALI[14,16] we observed that low dosing $(0.1 \mathrm{mg} / \mathrm{kg})$ of $\mathrm{FTY720}$ protected against MV-induced pulmonary hyperpermeability. In contrast to this observation, but in consistence with our findings in FTY720 challenged HUVEC monolayers, $2 \mathrm{mg} / \mathrm{kg}$ FTY720 evoked a dramatic increase of pulmonary permeability in VILI. In the $2 \mathrm{mg} / \mathrm{kg}$ FTY720 group ventilated for $2 \mathrm{~h}$, but not in the VILI control group marked endothelial injury and in particular endothelial apoptosis was detected by electron microscopy. In mice being treated with $0.1 \mathrm{mg} / \mathrm{kg} \mathrm{FTY720} \mathrm{and} \mathrm{ventilated} \mathrm{for} \mathrm{two} \mathrm{hours,} \mathrm{a} \mathrm{small} \mathrm{proportion} \mathrm{of} \mathrm{endothelial}$ cells also revealed signs of damage and apoptosis. These findings suggested that apoptosis might be one underlying mechanism for endothelial barrier breakdown observed in ventilated and FTY720-treated mice.

Neutrophil accumulation and activation may also contribute to the development of lung failure in pulmonary inflammation. Of note, TNF $\alpha$ induced, integrin mediated neutrophil recruitment has recently been shown to be SphK1 dependent[43]. However, neutrophil adhesion to TNF $\alpha$-activated endothelium was independent of the G-protein coupled S1P receptors[43], and we did not observe increased neutrophil accumulation in the lungs of ventilated mice after treatment with FTY720. As $2 \mathrm{mg} / \mathrm{kg}$ FTY720 did not increase permeability or evoke significant endothelial apoptosis in non-ventilated mice, our findings suggested a sensitization of the pulmonary vasculature by hyperoxia and VILI towards the barrier disrupting effect of FTY720. Cyclic stretch in VILI as well as hyperoxia may mediate proapoptotic signals [44]. However, several further mechanisms of the sensitization process may be proposed in the current context, including increased affinity of S1P2 or S1P3 to FTY720, and further studies are warranted to elucidate the interplay of hyperoxic VILI and FTY720. 
Some limitations of the current study have to be considered. Mice were ventilated with relatively high tidal volumes and without PEEP, which does not reflect recommended lung protective ventilation. Notably, the observation period in mouse models is usually limited to few hours as compared to ventilation of humans for days or weeks. In the applied model key mechanisms of VILI including pulmonary leukocyte recruitment and increase in lung permeability developed within the observation period, displaying suitability of the model for analysis of FTY720 effects in particular on pulmonary permeability within the limited observation period of $2 \mathrm{~h}$. Moreover, according to the baby lung concept of the acute respiratory distress syndrome (ARDS) [45], the forces affecting healthy lungs when being ventilated with $17 \mathrm{ml} / \mathrm{kg}$ bodyweight may apply in ventilated areas of inhomogeneously injured ARDS lungs even under lung protective ventilation.

\section{Conclusion}

The results of this study may have significant impact on the consideration of FTY720 dosing in humans. Different clinical studies analyzed FTY720 pharmacokinetics, pharmacodynamics[22] and the use of FTY720 for the treatment of graft rejection[3,5] or multiple sclerosis[6-9], and adverse effects related to impaired endothelial barrier integrity have not been reported. Notably, in none of these trials critically ill patients receiving MV were included. Although conclusions from in vitro findings and mouse experiments should be drawn carefully with respect to human patients, it is tempting to speculate that in ventilated, critically ill patients a lowered pulmonary toxicity threshold of FTY720 by VILI combined with systemic FTY720 accumulation may aggravate VILI evoked lung permeability. As FTY720 is a promising new drug candidate which gained FDA approval for the treatment of relapsing multiple sclerosis recently and is thus expected to enter clinical practice in 
the near future, it may be necessary to consider this possible side effect, to conduct appropriate clinical studies, and to revise optimal dosing of FTY720 for critically ill and mechanically ventilated patients.

\section{$\underline{\text { 6. Acknowledgments }}$}

The excellent technical assistance of J. Hellwig is greatly appreciated.

\section{Funding}

The work was supported in part by grants from the German Research Foundation to M.W. (SFB-TR84, project C3 and C6; OP 86/7-1), A.C.H. (SFB-TR84, project C5 and Z1a); S.H. (SFB-TR84, project C2 and C3; HI-789/6-1), N.S. (SFB-TR84) and the German Federal Ministry of Education and Research to S.H., H.C.M., N.S. and S.R. (Pneumonia Research Network on Genetic Resistance and Susceptibility for the Evolution of Severe Sepsis PROGRESS).

\section{References}

1. Brinkmann V: Sphingosine 1-phosphate receptors in health and disease: mechanistic insights from gene deletion studies and reverse pharmacology. Pharmacol Ther 2007, 115: 84-105.

2. Habicht A, Clarkson MR, Yang J, Henderson J, Brinkmann V, Fernandes S et al.: Novel insights into the mechanism of action of FTY720 in a transgenic model of allograft rejection: implications for therapy of chronic rejection. J Immunol 2006, 176: 36-42.

3. Budde K, Schmouder RL, Brunkhorst R, Nashan B, Lucker PW, Mayer T et al:: First human trial of FTY720, a novel immunomodulator, in stable renal transplant patients. J Am Soc Nephrol 2002, 13: 1073-1083.

4. Salvadori M, Budde K, Charpentier B, Klempnauer J, Nashan B, Pallardo LM et al.: FTY720 versus MMF with cyclosporine in de novo renal transplantation: a 1-year, randomized controlled trial in Europe and Australasia. Am J Transplant 2006, 6: 2912-2921. 
5. Tedesco-Silva H, Szakaly $P$, Shoker A, Sommerer C, Yoshimura N, Schena FP et al:: FTY720 versus mycophenolate mofetil in de novo renal transplantation: six-month results of a double-blind study. Transplantation 2007, 84: 885-892.

6. Cohen JA, Barkhof F, Comi G, Hartung HP, Khatri BO, Montalban X et al.: Oral fingolimod or intramuscular interferon for relapsing multiple sclerosis. N Engl J Med 2010, 362: 402-415.

7. Comi G, O'Connor P, Montalban X, Antel J, Radue EW, Karlsson G et al:: Phase II study of oral fingolimod (FTY720) in multiple sclerosis: 3-year results. Mult Scler 2010, 16: 197-207.

8. Kappos L, Antel J, Comi G, Montalban X, O'Connor P, Polman CH et al:: Oral fingolimod (FTY720) for relapsing multiple sclerosis. N Engl J Med 2006, 355: 1124-1140.

9. O'Connor P, Comi G, Montalban X, Antel J, Radue EW, de Vera A et al:: Oral fingolimod (FTY720) in multiple sclerosis: two-year results of a phase II extension study. Neurology 2009, 72: 73-79.

10. Wang L, Dudek SM: Regulation of vascular permeability by sphingosine 1-phosphate. Microvasc Res 2009, 77: 39-45.

11. Garcia JG, Liu F, Verin AD, Birukova A, Dechert MA, Gerthoffer WT et al:: Sphingosine 1-phosphate promotes endothelial cell barrier integrity by Edg-dependent cytoskeletal rearrangement. J Clin Invest 2001, 108: 689701.

12. Dudek SM, Jacobson JR, Chiang ET, Birukov KG, Wang P, Zhan X et al:: Pulmonary endothelial cell barrier enhancement by sphingosine 1phosphate: roles for cortactin and myosin light chain kinase. J Biol Chem 2004, 279: 24692-24700.

13. Singleton PA, Dudek SM, Chiang ET, Garcia JG: Regulation of sphingosine 1-phosphate-induced endothelial cytoskeletal rearrangement and barrier enhancement by S1P1 receptor, PI3 kinase, Tiam1/Rac1, and alphaactinin. FASEB J 2005, 19: 1646-1656.

14. Peng X, Hassoun PM, Sammani S, McVerry BJ, Burne MJ, Rabb H et al.: Protective effects of sphingosine 1-phosphate in murine endotoxininduced inflammatory lung injury. Am J Respir Crit Care Med 2004, 169: 1245-1251.

15. McVerry BJ, Peng X, Hassoun PM, Sammani S, Simon BA, Garcia JG: Sphingosine 1-phosphate reduces vascular leak in murine and canine models of acute lung injury. Am J Respir Crit Care Med 2004, 170: 987-993.

16. Liu HB, Cui NQ, Wang Q, Li DH, Xue XP: Sphingosine-1-phosphate and its analogue FTY720 diminish acute pulmonary injury in rats with acute necrotizing pancreatitis. Pancreas 2008, 36: e10-e15. 
17. Okazaki M, Kreisel F, Richardson SB, Kreisel D, Krupnick AS, Patterson GA et al.: Sphingosine 1-phosphate inhibits ischemia reperfusion injury following experimental lung transplantation. Am J Transplant 2007, 7: 751758.

18. Wadgaonkar R, Patel V, Grinkina N, Romano C, Liu J, Zhao Y et al:: Differential regulation of sphingosine kinases 1 and 2 in lung injury. $A m \mathrm{~J}$ Physiol Lung Cell Mol Physiol 2009, 296: L603-L613.

19. Dudek SM, Camp SM, Chiang ET, Singleton PA, Usatyuk PV, Zhao Y et al:: Pulmonary endothelial cell barrier enhancement by FTY720 does not require the S1P1 receptor. Cell Signal 2007, 19: 1754-1764.

20. Siehler S, Manning DR: Pathways of transduction engaged by sphingosine 1-phosphate through G protein-coupled receptors. Biochim Biophys Acta 2002, 1582: 94-99.

21. Sammani S, Moreno-Vinasco L, Mirzapoiazova T, Singleton PA, Chiang ET, Evenoski CL et al.: Differential effects of sphingosine 1-phosphate receptors on airway and vascular barrier function in the murine lung. $\mathrm{Am}$ J Respir Cell Mol Biol 2010, 43: 394-402.

22. Kovarik JM, Schmouder R, Barilla D, Riviere GJ, Wang Y, Hunt T: Multipledose FTY720: tolerability, pharmacokinetics, and lymphocyte responses in healthy subjects. J Clin Pharmacol 2004, 44: 532-537.

23. Kovarik JM, Schmouder RL, Serra D, Wang Y, Wiegand H, Dilzer SC et al.: FTY720 pharmacokinetics in mild to moderate hepatic impairment. $J$ Clin Pharmacol 2005, 45: 446-452.

24. Kovarik JM, Schmouder RL, Hartmann S, Riviere GJ, Picard F, Voss B et al:: Fingolimod (FTY720) in severe hepatic impairment: pharmacokinetics and relationship to markers of liver function. J Clin Pharmacol 2006, 46: 149-156.

25. Kovarik JM, Dole K, Riviere GJ, Pommier F, Maton S, Jin Y et al.: Ketoconazole Increases Fingolimod Blood Levels in a Drug Interaction via CYP4F2 Inhibition. J Clin Pharmacol 2008, 49: 212-8.

26. Hocke AC, Temmesfeld-Wollbrueck B, Schmeck B, Berger K, Frisch EM, Witzenrath $\mathrm{M}$ et al.: Perturbation of endothelial junction proteins by Staphylococcus aureus alpha-toxin: inhibition of endothelial gap formation by adrenomedullin. Histochem Cell Biol 2006, 126: 305-316.

27. Hocke AC, Hartmann IK, Eitel J, Optiz B, Scharf S, Suttorp N et al:: Subcellular expression pattern and role of IL-15 in pneumococci induced lung epithelial apoptosis. Histochem Cell Biol 2008, 130: 165-176.

28. Muller HC, Witzenrath M, Tschernig T, Gutbier B, Hippenstiel S, Santel A et al:: Adrenomedullin attenuates ventilator-induced lung injury in mice. Thorax 2010, 65: 1077-1084. 
29. Muller HC, Hellwig K, Rosseau S, Tschernig T, Schmiedl A, Gutbier B et al:: Simvastatin attenuates ventilator-induced lung injury in mice. Crit Care 2010, 14: R143.

30. Sanchez T, Estrada-Hernandez T, Paik JH, Wu MT, Venkataraman K, Brinkmann $V$ et al: : Phosphorylation and Action of the Immunomodulator FTY720 Inhibits Vascular Endothelial Cell Growth Factor-induced Vascular Permeability. J Biol Chem 2003, 278: 47281-47290.

31. Camp SM, Bittman R, Chiang ET, Moreno-Vinasco L, Mirzapoiazova T, Sammani S et al.: Synthetic analogs of FTY720 [2-amino-2-(2-[4octylphenyl]ethyl)-1,3-propanediol] differentially regulate pulmonary vascular permeability in vivo and in vitro. J Pharmacol Exp Ther 2009, 331: 54-64.

32. Sanchez T, Skoura A, Wu MT, Casserly B, Harrington EO, Hla T: Induction of vascular permeability by the sphingosine-1-phosphate receptor-2 (S1P2R) and its downstream effectors ROCK and PTEN. Arterioscler Thromb Vasc Biol 2007, 27: 1312-1318.

33. Brinkmann V, Davis MD, Heise CE, Albert R, Cottens S, Hof R et al.: The immune modulator FTY720 targets sphingosine 1-phosphate receptors. $J$ Biol Chem 2002, 277: 21453-21457.

34. Bohler T, Guillebaud J, Etienne L, Canivet C, Kamar N, Rostaing L et al.: Effect of FTY720 on apoptosis of smooth muscle cells. Transplant Proc 2007, 39: 2624-2626.

35. Hung JH, Lu YS, Wang YC, Ma YH, Wang DS, Kulp SK et al.: FTY720 induces apoptosis in hepatocellular carcinoma cells through activation of protein kinase C delta signaling. Cancer Res 2008, 68: 1204-1212.

36. Puneet P, Yap CT, Wong L, Lam Y, Koh DR, Moochhala S et al.: SphK1 regulates proinflammatory responses associated with endotoxin and polymicrobial sepsis. Science 2010, 328: 1290-1294.

37. Daniel C, Sartory N, Zahn N, Geisslinger G, Radeke HH, Stein JM: FTY720 ameliorates Th1-mediated colitis in mice by directly affecting the functional activity of CD4+CD25+ regulatory T cells. J Immunol 2007, 178: 2458-2468.

38. Galvao VR, Ginoza M, Franco M, Burdmann EA, Bueno V: Prolonged administration of FTY720 does not cause renal toxicity in mice. Transplant Proc 2005, 37: 112-113.

39. Kaudel CP, Frink M, van Griensven M, Schmiddem U, Probst C, Bergmann S et al:: FTY720 application following isolated warm liver ischemia improves long-term survival and organ protection in a mouse model. Transplant Proc 2007, 39: 493-498.

40. Esteban A, Anzueto A, Frutos F, Alia I, Brochard L, Stewart TE et al.: Characteristics and outcomes in adult patients receiving mechanical ventilation: a 28-day international study. JAMA 2002, 287: 345-355. 
41. Bhandari V, Choo-Wing R, Lee CG, Zhu Z, Nedrelow JH, Chupp GL et al.: Hyperoxia causes angiopoietin 2-mediated acute lung injury and necrotic cell death. Nat Med 2006, 12: 1286-1293.

42. Verbrugge SJ, Lachmann B, Kesecioglu J: Lung protective ventilatory strategies in acute lung injury and acute respiratory distress syndrome: from experimental findings to clinical application. Clin Physiol Funct Imaging 2007, 27: 67-90.

43. Sun WY, Pitson SM, Bonder CS: Tumor necrosis factor-induced neutrophil adhesion occurs via sphingosine kinase-1-dependent activation of endothelial \{alpha\}5\{beta\}1 integrin. Am J Pathol 2010, 177: 436-446.

44. Hammerschmidt S, Kuhn H, Grasenack T, Gessner C, Wirtz H: Apoptosis and necrosis induced by cyclic mechanical stretching in alveolar type II cells. Am J Respir Cell Mol Biol 2004, 30: 396-402.

45. Gattinoni L, Pesenti A: The concept of "baby lung". Intensive Care Med 2005, 31: 776-784. 


\section{Figure legends}

Fig. 1 Transcellular electrical resistance of FTY720 treated endothelial cell monolayers

HUVECs, grown to confluence on gold microelectrodes to measure transendothelial electrical resistance (TER) were stimulated with FTY720 in concentrations of 0.01 , $0.1,1,10,100 \mu \mathrm{M}$ or with solvent (ctr.). a) One representative experiment is shown. Low dose FTY720 $(0.01,0.1$ and $1 \mu \mathrm{M})$ enhanced endothelial barrier function, whereas $100 \mu \mathrm{M}$ FTY720 induced rapid barrier breakdown. $10 \mu \mathrm{M}$ FTY720 initially enhanced cell layer integrity but evoked barrier breakdown after $>60 \mathrm{~min}$ of stimulation. b) These observations were confirmed by area under the curve (AUC) analysis. c) Bar graphs depict mean \pm sem of TER values at the time points 60,90 , 120,180 min. ( ${ }^{*} p<0.05$ vs ctr., $\left.\# p<0.05\right) ;(n=4$, triplet or quartets were used in each replication of the experiment)

Fig. 2 High concentrations of FTY720 induced apoptosis in endothelials cells Confluent HUVECs were incubated with FTY720 $(1,10$ or $100 \mu \mathrm{M}$ as indicated) or solvent for 60min. a) F-actin staining. HUVECs stimulated with $1 \mu \mathrm{M}$ FTY720 showed no significant changes as compared to control, whereas incubation with $100 \mu \mathrm{M}$ FTY720 induced disruption of HUVEC monolayers with intercellular gap formation and detachment of cells from glass slides. b) Apoptosis was detected by TUNEL staining in cells stimulated with $100 \mu \mathrm{M}$ FTY720. Staurosporin $(10 \mu \mathrm{M})$ was used as positive control for apoptosis. Staurosporin treated cells, in which the enzymatic reaction evoking fluorescence was not performed, confirmed the TUNEL signal specific. c) Apoptosis was induced by $100 \mu$ M FTY720 as indicated by procaspase- 3 degradation. $a-b)$ representative images of three independent experiments with similar results are shown. 
Fig. 3 FTY720 treatment did not evoke lung injury in non-ventilated mice

Mice were treated with $0.1 \mathrm{mg} / \mathrm{kg}$ or $2 \mathrm{mg} / \mathrm{kg}$ FTY720, or solvent (ctr.). BAL was performed and blood was drawn $2.5 \mathrm{~h}$ after the initial dosage, matching the time point of sample collection in the MV experiments.(Fig. 4) a) FTY720 did not alter pulmonary vascular permeability $(n=5)$. b) Circulating lymphocytes were decreased by FTY720 treatment while neutrophils (PMN) and monocytes were unaffected. $\left({ }^{*}<0.05, \mathrm{n}=5\right)$

Fig. 4 FTY720 aggravated lung permeability in mechanically ventilated mice VILI was induced in mice treated with $0.1 \mathrm{mg} / \mathrm{kg}$ or $2 \mathrm{mg} / \mathrm{kg} \mathrm{FTY720,} \mathrm{or} \mathrm{solvent} \mathrm{(ctr.)}$ by $2 \mathrm{~h}$ of mechanical ventilation (MV). (NV: non ventilated mice). a) MV evoked pulmonary hyperpermeability. Treatment with $0.1 \mathrm{mg} / \mathrm{kg}$ FTY720 reduced permeability while $2 \mathrm{mg} / \mathrm{kg}$ FTY720 further increased permeability. (\#\# $p<0.01$ vs. $\left.N V,{ }^{*} p<0.05,{ }^{*} p<0.01 ; n=5-6\right)$ b) Oxygenation in mice after $2 h$ of $M V\left({ }^{*} p<0.05 ; n=\right.$ 5-6) c) BAL neutrophils (PMN) were quantified. FTY720 did not affect VILI induced neutrophil invasion to the lung. ( ${ }^{*} \mathrm{p}<0.05$ vs. $N V, n=5-6$ ).

Fig. 5 FTY720 induced endothelial damage and apoptosis in mechanically ventilated mice

Non ventilated (NV) and ventilated (MV) mice were treated with $0.1 \mathrm{mg} / \mathrm{kg}$ or $2 \mathrm{mg} / \mathrm{kg}$ FTY720, or solvent (ctr.). Lungs were analyzed by electron microscopy. a) NV ctr. mice displayed intact endothelium and epithelium. b) Epithelial edema was observed after $2 \mathrm{~h}$ of MV in ctr. mice while endothelial injury was observed only sporadically. c) Intact endothelial and epithelial integrity in NV mice treated with $0.1 \mathrm{mg} / \mathrm{kg} \mathrm{FTY720.}$ d) Epithelial edema and occasional endothelial apoptosis after MV and FTY720 
treatment $(0.1 \mathrm{mg} / \mathrm{kg})$ e) Intact alveolar epithelium and sporadical endothelial apoptosis in lungs of NV mice treated with $2 \mathrm{mg} / \mathrm{kg} \mathrm{FTY720.} \mathrm{f)} \mathrm{MV} \mathrm{in} \mathrm{mice} \mathrm{treated}$ with 2mg/kg FTY720 resulted in major endothelial injury and endothelial apoptosis in addition to prominent epithelial injury. (AE I = Alveolar epithelial cell type I; AE II = Alveolar epithelial cell type II; E = Endothelium; * = Epithelial swelling; + = Endothelial swelling; NG = Neutrophil Granulocyte; $G=$ Apoptotic Granulocyte; AP.E = Apoptotic Endothelium. Representative images of three independent experiments are shown) 
a

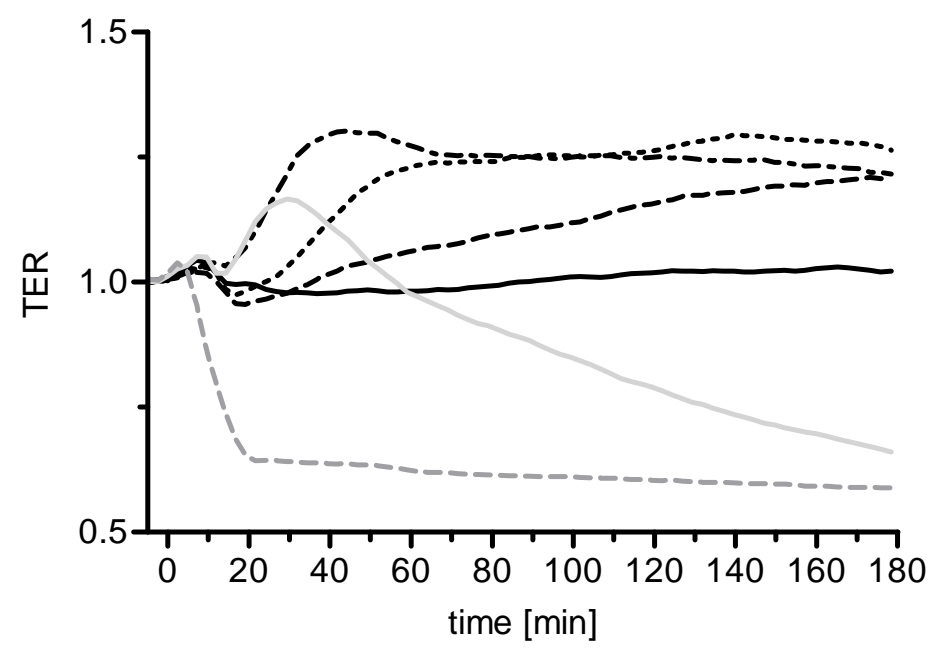

c

$60 \mathrm{~min}$

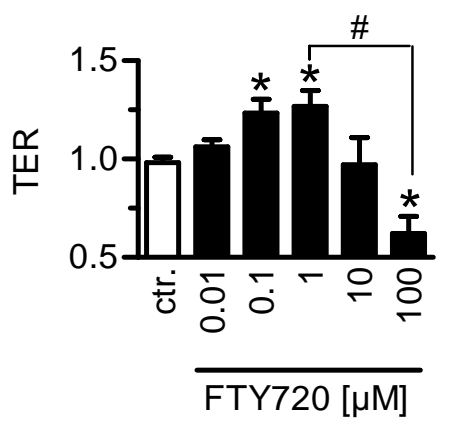

$\underline{90 \mathrm{~min}}$

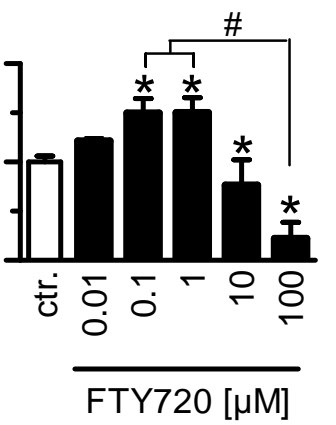

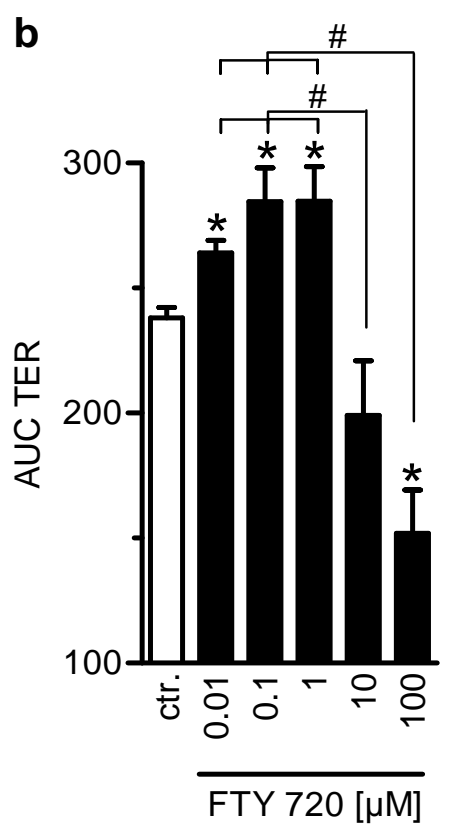

$120 \mathrm{~min}$

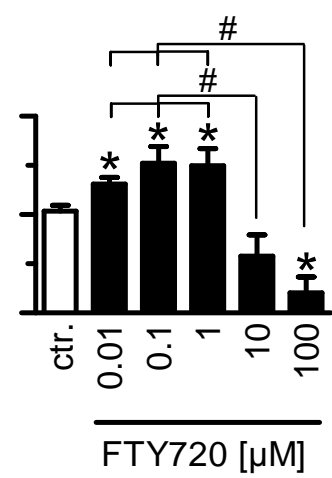

$180 \mathrm{~min}$

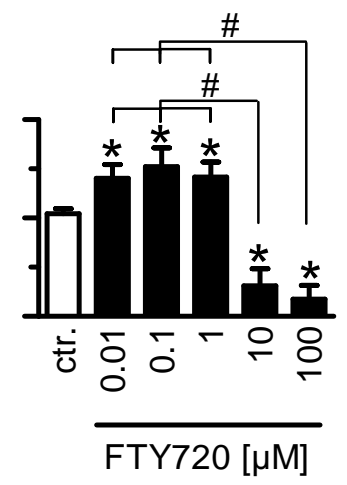




\section{a}

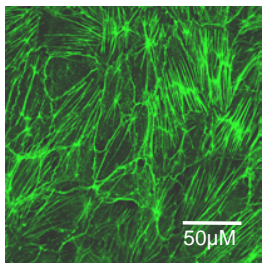

solvent

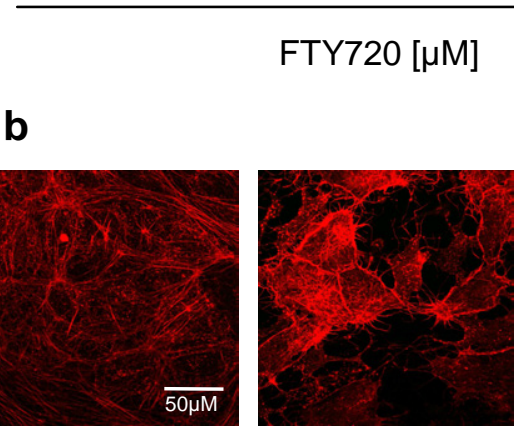

Staurosporin $10 \mu \mathrm{M}$ Staurosporin $10 \mu \mathrm{M}$

(- TUNEL)

solvent

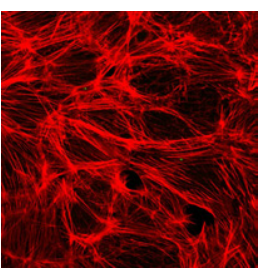

1

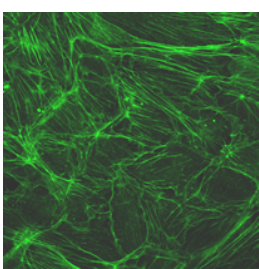

1

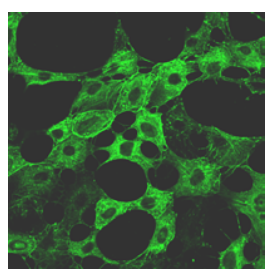

100

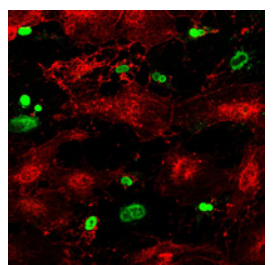

(+TUNEL)

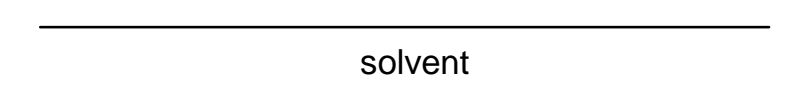

\begin{tabular}{lll}
1 & 10 & 100 \\
\hline
\end{tabular}

FTY720 [ $\mu \mathrm{M}]$

C

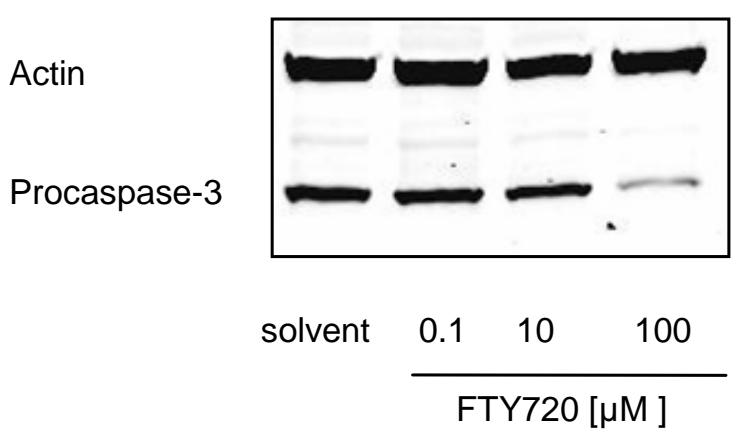


a
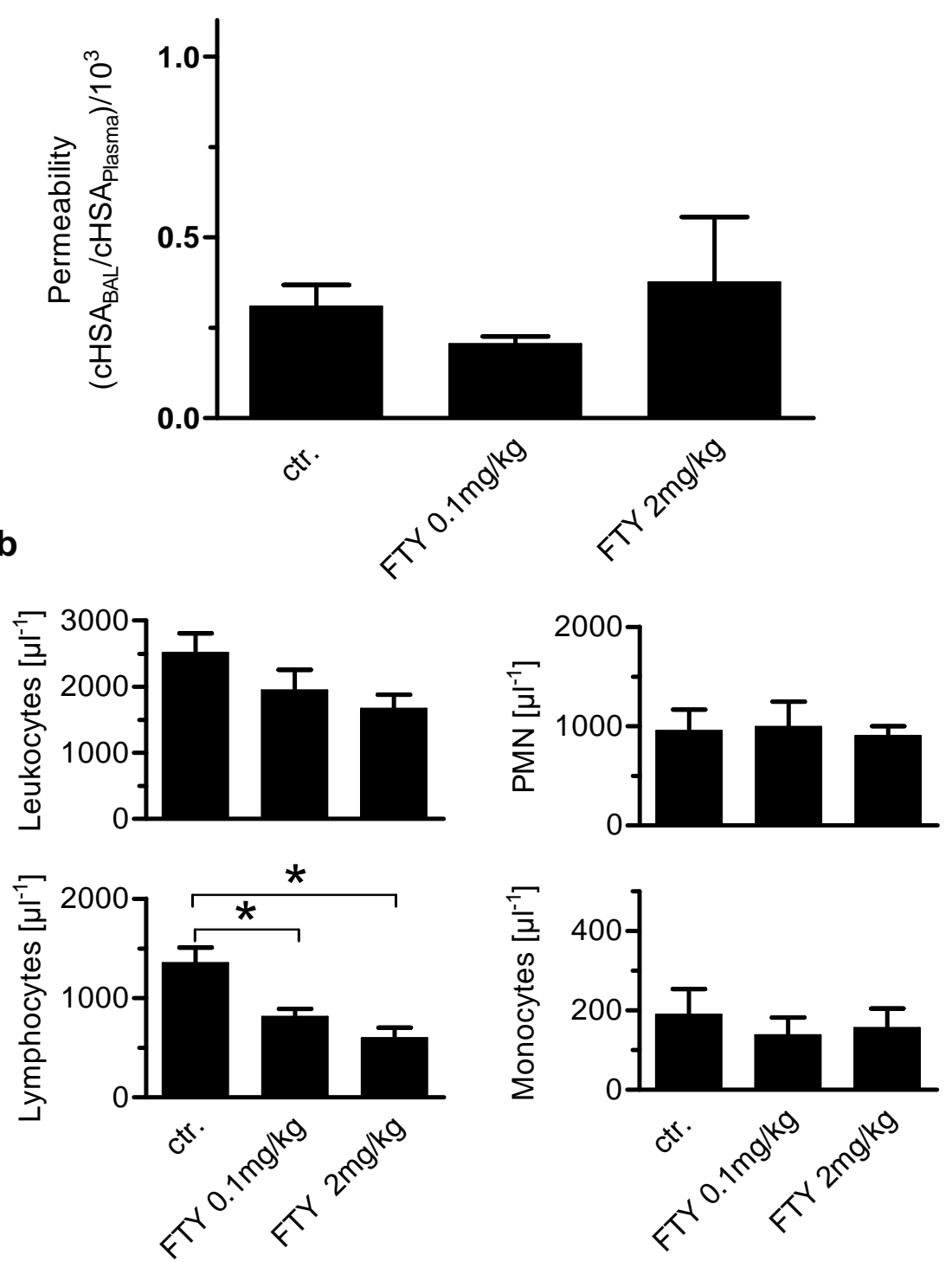

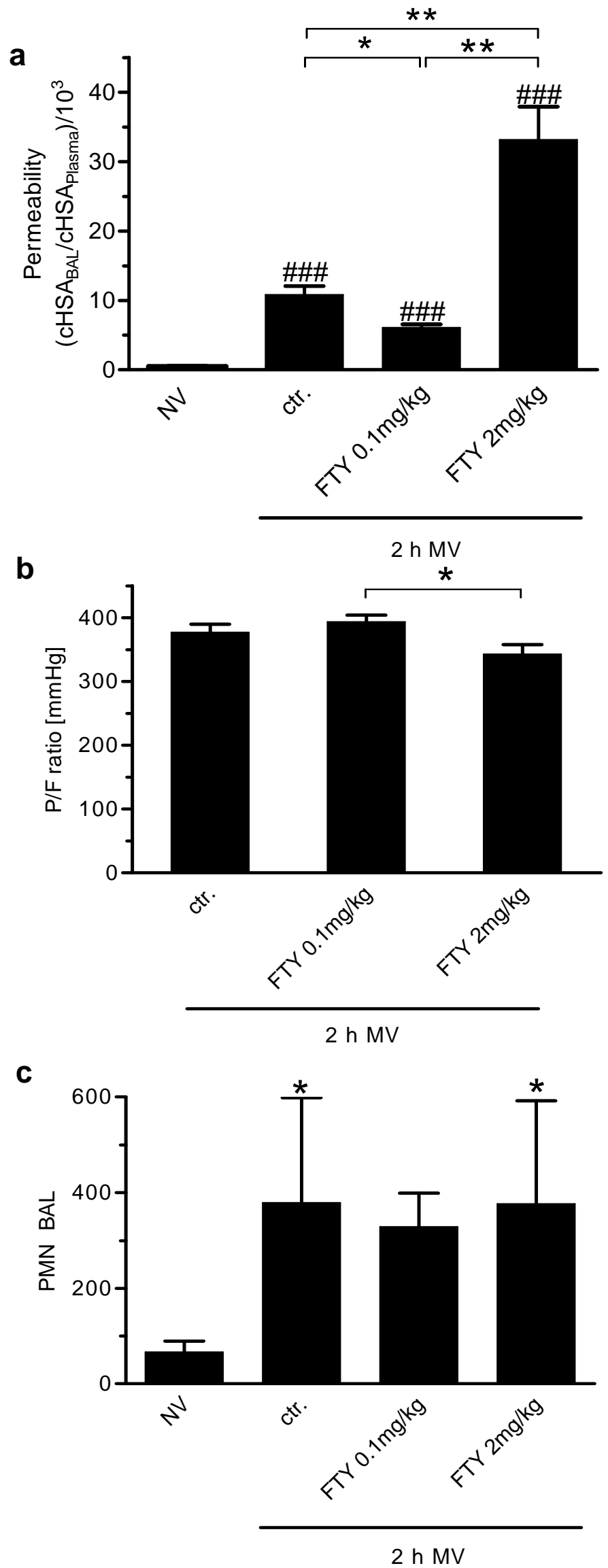
NV

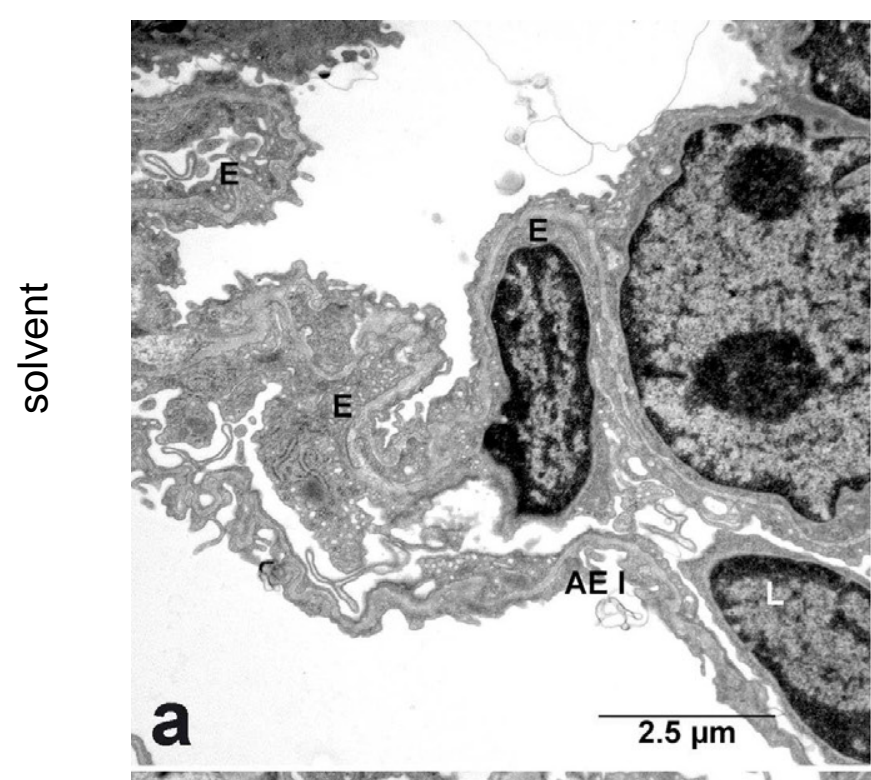

VILI

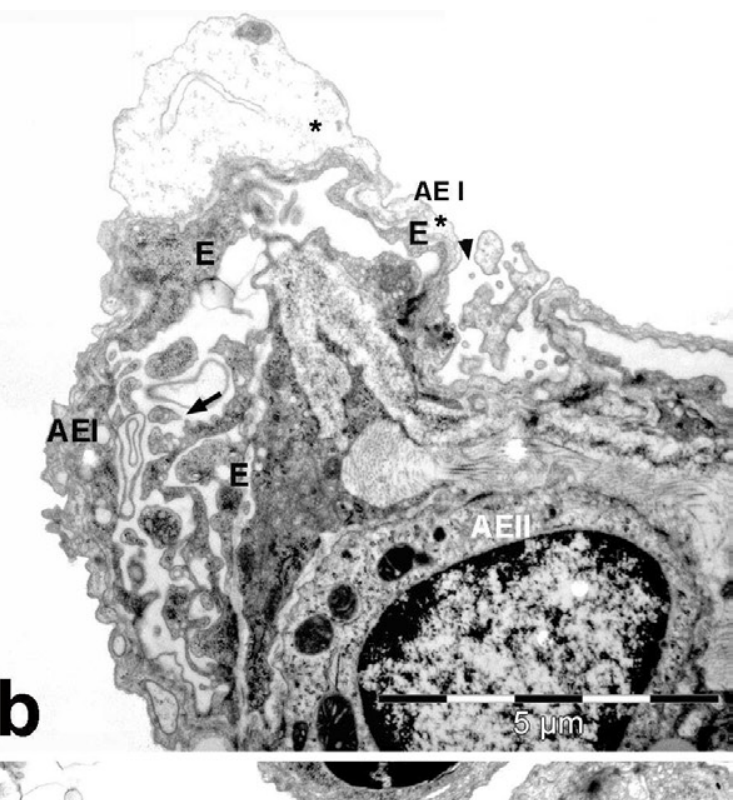

AE I

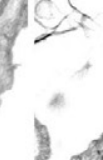

ํㅗㄴ

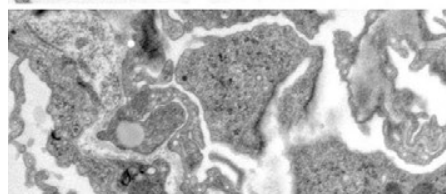

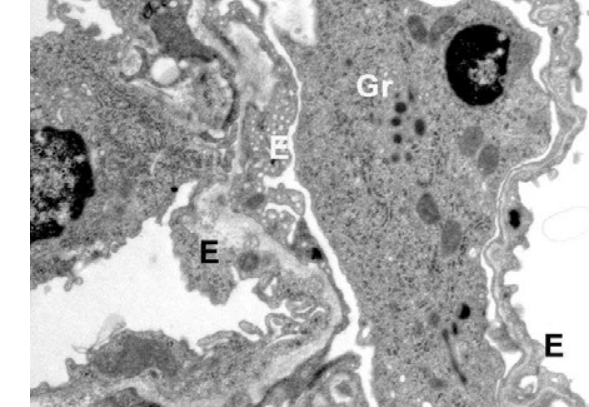

- 1 - niges

ore C. 6 of v.

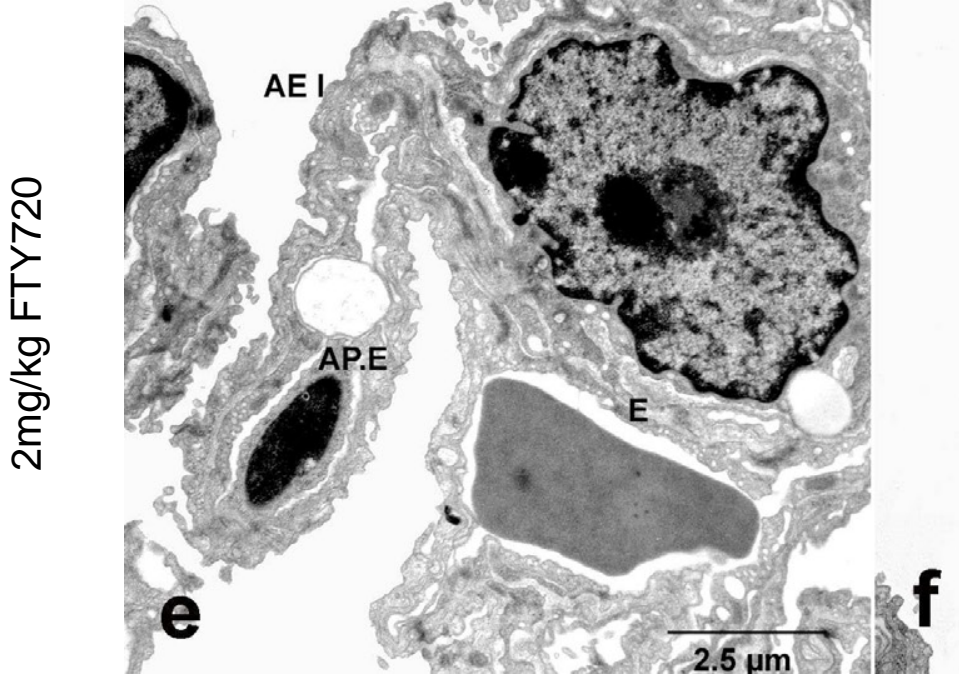

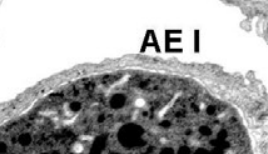

का iो 2
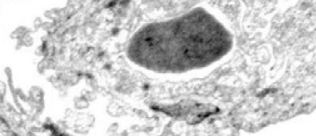

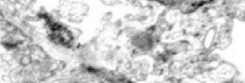
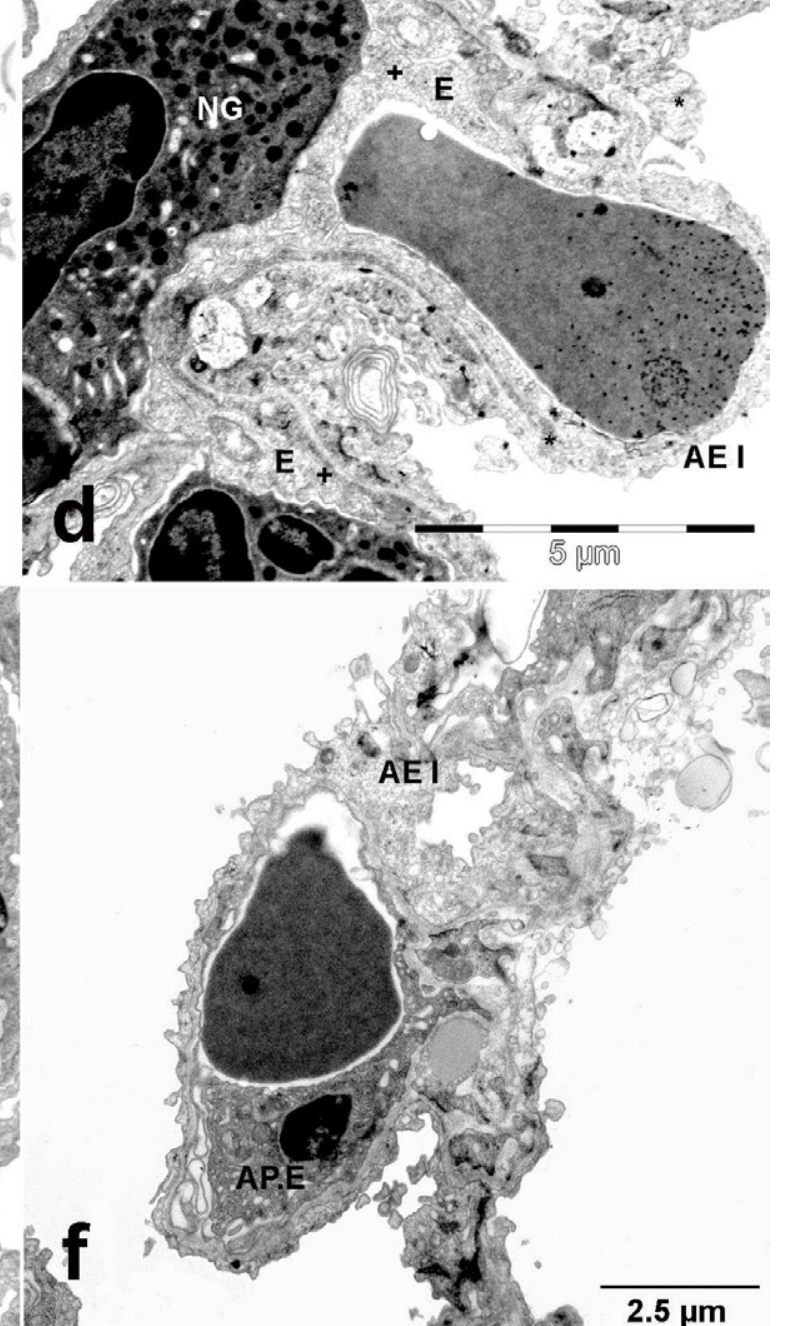